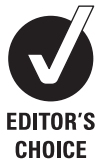
CHOICE

\title{
Responsibility of sport and exercise medicine in preventing and managing chronic disease: applying our knowledge and skill is overdue
}

\author{
Gordon 0 Matheson, ${ }^{1}$ Martin Klügl, ${ }^{1}$ Jiri Dvorak, ${ }^{2,3}$ Lars Engebretsen, ${ }^{4}$ \\ Willem H Meeuwisse, ${ }^{5}$ Martin Schwellnus, ${ }^{6}$ Steven N Blair, ${ }^{7}$ Willem van Mechelen, ${ }^{8}$ \\ Wayne Derman, ${ }^{6}$ Mats Börjesson, ${ }^{9,10}$ Fredrik Bendiksen, ${ }^{11}$ Richard Weiler ${ }^{12}$
}

'Department of Orthopaedic Surgery, Division of Sports

Medicine \& Human Performance Laboratory, Stanford University

School of Medicine, Stanford, California, USA

${ }^{2}$ Schulthess Clinic, Zurich, Switzerland

${ }^{3}$ FIFA Medical Assessment \& Research Center (F-MARC). Zurich, Switzerland

${ }^{4}$ Orthopaedic Center, Ullevål University Hospital, University of Oslo, Norway

${ }^{5}$ Sport Injury Prevention

Research Centre, University of Calgary, Calgary, Alberta,

Canada

${ }^{6}$ UCT Research Unit for Exercise Science \& Sports Medicine, Department of Human Biology, University of Cape Town, Newlands, South Africa ${ }^{7}$ Departments of Exercise Science and Epidemiology \& Biostatistics, Arnold School of Public Health, University of South Carolina, Columbia, South Carolina, USA

${ }^{8}$ Department of Public and Occupational Health and EMGO Institute for Health \& Care Research, VU University Medical Center, Amsterdam, The Netherlands

${ }^{9}$ Astrands Laboratory, The Swedish School of Sports and Health Sciences and Karolinska University Hospital, Stockholm, Sweden

${ }^{10}$ Department of Acute and Cardiovascular Medicine,

Sahlgrenska University Hospital/Ostra, Goteborg,

Sweden

${ }^{11}$ Oslo Sports Trauma Research Center, Norwegian School of Sport Sciences, Oslo, Norway ${ }^{12}$ Sport \& Exercise Medicine, Homerton University Hospital NHS Trust, London, UK

\section{Correspondence to} Dr Gordon 0 Matheson, Sports Medicine Center. 341 Galvez Street, Stanford, CA 94304, USA; gord@stanford.edu

Accepted 25 August 2011 Published Online First 26 September 2011

\section{ABSTRACT}

Background The rapidly increasing burden of chronic disease is difficult to reconcile with the large, compelling body of literature that demonstrates the substantial preventive and therapeutic benefits of comprehensive lifestyle intervention, including physical activity, smoking cessation and healthy diet. Physical inactivity is now the fourth leading independent risk factor for death caused by non-communicable chronic disease. Although there have been efforts directed towards research, education and legislation, preventive efforts have been meager relative to the magnitude of the problem. The disparity between our scientific knowledge about chronic disease and practical implementation of preventive approaches now is one of the most urgent concerns in healthcare worldwide and threatens the collapse of our health systems unless extraordinary change takes place.

Findings The authors believe that there are several key factors contributing to the disparity. Reductionism has become the default approach for healthcare delivery, resulting in fragmentation rather than integration of services. This, in turn, has fostered a disease-based rather than a health-based model of care and has produced medical school curricula that no longer accurately reflect the actual burden of disease. Trying to 'fit' prevention into a disease-based approach has been largely unsuccessful because the fundamental tenets of preventive medicine are diametrically opposed to those of disease-based healthcare.

Recommendation A clinical discipline within medicine is needed to adopt disease prevention as its own reason for existence. Sport and exercise medicine is well positioned to champion the cause of prevention by promoting physical activity.

Conclusion This article puts forward a strong case for the immediate, increased involvement of clinical sport and exercise medicine in the prevention and treatment of chronic disease and offers specific recommendations for how this may begin.

\section{INTRODUCTION}

Clinical sport and exercise medicine has grown remarkably over the past three decades with high-quality scientific meetings, excellent clinical training programmes, codes of conduct, ${ }^{1}$ clinical guidelines and a robust research literature. ${ }^{2}$ During its nascence, sports medicine was the harbinger of a new approach to medicine with the hope that the knowledge and skills gleaned from the care of athletes would be translated to the general population for the purpose of improving physical function, health and vitality and countering the rapidly increasing prevalence of chronic diseases. By and large, this has not yet occurred.

The reasons for the disparity between what we know regarding the health benefits of physical activity and exercise and the lack of progress implementing behavioural change are complex. ${ }^{3-9}$ The purpose of this article is to review obstacles that may be hampering progress with these efforts and the role that clinical sport and exercise medicine should play.

Sport and exercise medicine physicians are trained to understand the importance of lifestyle changes (including physical activity and exercise) for maintaining and promoting health, restoring function, increasing physical capacity and vitality and preventing and treating disease. The emerging discipline of clinical sport and exercise medicine is poised to substantially increase its emphasis in chronic disease prevention and management.

We begin with a short review of the scientific support for physical activity and exercise as primary determinants of health, then discuss systemic problems with the implementation of a preventive approach in today's healthcare delivery models, and finally offer possible solutions to benefit global health.

\section{PHYSICAL ACTIVITY, EXERCISE AND CHRONIC DISEASE}

Physical activity, exercise and health

Physical activity has numerous positive effects on health. ${ }^{10-12}$ Regular, moderate-intensity physical activity reduces morbidity and lowers mortality through effects that are primary (reducing the development of disease), ${ }^{13-18}$ secondary (early detection and treatment to minimise morbidity) ${ }^{19-21}$ and tertiary (reduction of disease-related complications and restoration of function). ${ }^{22-24}$ The available data indicate widespread generalisability across other countries, cultures, gender, age and ethnicity. ${ }^{2526}$

Physical activity is the most effective single therapy among a suite of comprehensive lifestyle interventions that include nutrition, therapeutic education and psychosocial intervention. Even physical activity such as walking or cycling for transportation are important determinants of longevity. ${ }^{27}$ The impact of physical activity is 
profound on the quality of life for those with chronic diseases $^{28}$ and is also important for improving quality of life, physical independence and reducing falls in the ageing populations. ${ }^{29-32}$

Physical activity is one lifestyle intervention; others include proper diet, smoking cessation and alcohol intake. The success of implementing lifestyle change lies in the comprehensive nature of the intervention, and for that reason, focusing on physical activity alone is too narrow. However, lifestyle risk factors tend to cluster, and physical activity has concomitant effects on other lifestyle interventions such as smoking cessation, ${ }^{33}$ weight loss and the adoption of other healthy behaviours. ${ }^{34}$ In addition, there are wider, indirect benefits evident through improved work productivity ${ }^{35}$ and reduced absenteeism. 3637

Although more research will increase our understanding of the effect of exercise on the pathophysiology of chronic disease, motor competence and organ-specific effects, enough is now known about its benefits that it is irresponsible and unethical to not advocate for its widespread adoption. Indeed, numerous clinical guidelines recommend physical activity promotion and lifestyle counselling in their first treatment recommendation, bringing clinical responsibility to adopt these interventions with medical-legal considerations. ${ }^{38}$

\section{The disparity}

Over the past three decades, chronic disease has increased markedly. Major progress in healthcare and public health over the past century, associated with sustained economic growth, has contributed to improvements in some aspects of population health and longevity but has failed to simultaneously address the increase in chronic diseases linked to this progress in OECD (The Organization for Economic Co-operation and Development is an international economic organisation of 34 countries founded in 1961 to stimulate economic progress and world trade. It defines itself as a forum of countries committed to democracy and the market economy, providing a platform to compare policy experiences, seeking answers to common problems, identifying good practices, and coordinating domestic and international policies of its members. (Source: Wikipedia.org).) countries. ${ }^{39}$ The increase in lifestyle-related diseases counteracts the effects of improved pharmacologic and other forms of treatments to a varying extent, ${ }^{40}$ resulting in an increase in chronic disease burden.

Despite the large body of scientific data supporting the health benefits of physical activity to prevent and treat chronic disease, only $32 \%$ of adults in the USA were engaged in regular physical activity in $2008^{41}$ and at least half of the populace of Canada fail to meet national recommended guidelines. ${ }^{42}$ Chronic lifestyle-related disease accounts for $60 \%$ of deaths worldwide ${ }^{43}$ and $70 \%$ of deaths in the USA. ${ }^{44}$ In 2005 , nearly $50 \%$ of the entire population of the USA had at least one chronic illness. ${ }^{45}$ Approximately $25 \%$ of people with chronic conditions have one or more daily activity limitations. ${ }^{46}$

Physical inactivity and sedentary living are now a global 'non-communicable' disease. ${ }^{47-49}$ The WHO predicts that lifestyle-related chronic diseases - mainly cardiovascular disease, diabetes, cancer and chronic respiratory disease - will account for two thirds of all deaths globally in the next 25 years. ${ }^{50}$ Obesity rates are still lower in major non-OECD countries but growing at a similar pace as in higher income countries, especially in urban areas. ${ }^{51}$ The amount of energy consumed in food has not changed considerably since the 1970s, 52 but the energy expended in exercise and physical activity has decreased ${ }^{53}$ parallel to the increase in obesity. Changes in occupation over the past 50 years in the USA show a substantial reduction in occupational energy expenditure. ${ }^{54}$ This decline in energy expended on the job is enough to explain the obesity epidemic.

The economic consequences of the increase in chronic disease - driven by productivity reduction and the increased cost to workforces caused by these diseases - are substantial and, as such, are a major barrier to human development. ${ }^{55-57}$ The WHO estimates that between 2005 and 2015, income loss could increase to as much as US\$558 billion in China, US\$237 billion in India, US\$303 billion in Russia and US\$33 billion in the UK. ${ }^{58}$ If the current rate of increase in obesity continues in the USA, the total healthcare costs attributable are anticipated to double every decade, reaching US\$860960 billion by 2030. ${ }^{59}$ The UN General Assembly recognises the importance of chronic diseases as a development issue and has recently hosted the first high-level meeting on these diseases with the participation of heads of state and government. 60

\section{Attempts to address the disparity}

Although it may seem intuitive that knowledge regarding the benefits of physical activity would somehow translate into behavioural change, this has not been the case. ${ }^{61}$ The research community involved in trying to understand this disparity has largely determined that issues such as concordance, adherence to prescribed treatments and community intervention have not worked. ${ }^{62}$ Mass media campaigns, including print, TV or web programmes, may increase awareness of the issue but offer only limited impact on physical activity and exercise behaviour. ${ }^{63-67}$ Even current population-based policies mandating increased physical activity and physical education lessons in schools are unlikely to have a significant effect on stemming the increasing prevalence of childhood obesity. ${ }^{68}$ Advancing wellness in the workplace has been the focus of several studies, and the number of health promotion programmes in this setting continues to grow. ${ }^{6970}$ Recently, a report from the World Economic Forum suggested that workplace wellness schemes could prevent up to $40 \%$ of non-communicable diseases. ${ }^{71} 72$ Additional research is still needed. ${ }^{73}$

Governments have implemented a wide range of interventions to fight obesity at national and local levels. However, there is little to no evidence as to the effectiveness of these interventions, and virtually no evidence of their efficiency and distributional impact. ${ }^{39}$ Physician counselling of at-risk individuals might have a large health impact but is one of the most expensive interventions and so far has only been associated with short-term increases in physical activity. ${ }^{39}$ Furthermore, such advice is not offered systematically but is typically provided in response to specific individual demands. ${ }^{72} 74$

In an attempt to remedy the situation through change to individual health-related behaviours, the OECD and WHO separated obesity and other risk factor interventions for chronic disease into three categories ${ }^{51}$ : (1) health education and promotion (eg, mass media campaigns, school-based and worksite interventions); (2) regulatory and fiscal measures; and (3) primary care-based interventions (eg, physician counselling). Unfortunately, interventions are often inadequately implemented and widely underused. ${ }^{49}$ 


\section{SYSTEMIC PROBLEMS IMPLEMENTING A HEALTH-BASED MODEL OF CARE}

The increasing burden of chronic conditions is an inescapable reality of ageing populations and deserves attention. ${ }^{75}$ Not nearly enough effort has been directed to issues within healthcare, systemic in nature, that represent serious impediments to adequately address this burden. These are (1) the reductionist approach to thinking within medical science, which has become the default approach in healthcare delivery; (2) the financing and planning of current disease- and event-based models of care; (3) the lack of disease-burden matched curricula for training health professionals; (4) the absence of a tailored distribution channel to connect knowledge with the delivery of that knowledge to patients; and (5) the complexity of changing human behaviour.

\section{Reductionism by default}

Historically, the intuitive art of medicine has become 'precise' science by using the reductionist approach to divide complex problems into smaller, simpler, and thus more understandable component parts. Once these 'reduced' systems were understood, an avenue for clinical application would typically open. The reductionist approach, accompanied by technological advances in diagnosis and treatment, helped overcome the biggest challenge facing medicine: shifting the culture from intuitive to precision medicine; converting a complex process into simplified, rules-based work. ${ }^{7677}$

Reductionism has become the default way of thinking in the delivery of healthcare, and it pervades each medical science today with claims of a linear input-output, offering one potential singular target for medical treatment for every disease. ${ }^{78}$ However stupendous the progress of the reductionist approach has been to advance medical science, its limitations have been exposed by the crisis of chronic disease prevention and management. Reductionism does not foster the integration of different specialties and therefore impedes the multidisciplinary approach that is necessary for the prevention of chronic disease. Although it promotes the search for objective measures of chronic disease, it ignores the reality that health is a spectrum ranging from complete wellness to multiple disease states. Often, by the time a diagnosis is made and reductionist interventions (often pharmaceutical) are initiated, mortality and morbidity will be resistant to these interventions (eg, diabetes $^{79}$ ). This is neither cost effective nor a logical expenditure of scarce resources. Medicine continues to operate within the reductionist paradigm. This is precisely why prevention cannot be integrated into the current disease-based system. Its fundamental principles are so different from disease-based healthcare that the culture clash is, in and of itself, an obstacle.

\section{Delivery of disease-based and event-based models of healthcare}

A natural extension of the default reductionist approach to healthcare is the disease-based model or, more recently termed, event-based medicine. The flaws with the diseasebased model of health and its impact on health intervention efficacy are often underestimated ${ }^{80}$ : (1) the overuse of well-reimbursed services and the underuse of less lucrative services ${ }^{81}$; (2) a medical culture that places little value on activities such as care coordination and medical direction that are not explicitly reimbursed ${ }^{82}$; and (3) a fragmented delivery system that patients and providers find increasingly difficult to navigate. ${ }^{81}$
Our current disease-based medical system, now a century old, was built to uncover disease mechanisms for acute episodes of sickness; it was never designed to address important issues outside of disease that cause health problems. The resources, processes and business plans for doctor's offices and hospitals are optimised to manage acute crises or episodes, using a feefor-service payment system in many parts of the world. These formulae bill costs for input rather than output, because they are based on activities, not the value created. ${ }^{83} 84$ Many treatments generate benefits that may justify their costs, notably in terms of quality of life. ${ }^{85}$ But the use of quotas in diseasebased treatment has been 'abysmal'. ${ }^{86}$ The financial planning and reward systems are markedly tilted towards running the existing disease-based model of care while largely ignoring the impact on the actions and outcomes it created. ${ }^{87}$ Currently, in the USA, there are more than 9000 billing codes for individual procedures and units of care, but none of them for patient compliance or for helping patients stay well. Consequently, only $8 \%$ of patient office visits include counselling or education related to physical activity. ${ }^{88}$ Although the new ICD10 coding system now includes annual wellness screenings in its 150000 code options, the acute, event-based, fee-for-service paradigm that rewards volume of care rather than quality or efficiency is unchanged. 8990

In addition to being fragmentary rather than integrative with respect to comprehensive interventions for chronic disease prevention and treatment, reductionism builds walls. Reductionism results naturally in a silo effect in which reductionist components revolve around their own centres. Individual providers have little financial incentive and infrastructure support to step out of their silos to coordinate care across patients' conditions, and care settings have limited ability to influence the behaviour of other providers. ${ }^{91}$ For example, the American Geriatric Association recently labelled sarcopaenia as a disease rather than see it as a consequence of sedentary living associated with ageing. ${ }^{92}{ }^{93}$ Mechanisms to quantify the extent of sarcopaenia (CT or MRI measurement of skeletal muscle mass or cross-sectional area) are relatively easy to develop. Approval for anabolic medication to promote protein synthesis is easy to obtain. But the best medicine to address the underlying cause is prevention and rehabilitation through regular physical activity ${ }^{94}$ The disease-based approach to healthcare occurs in both wealthy and developing countries. ${ }^{95}$ Healthcare systems in developing countries such as sub-Saharan Africa are poorly equipped to manage non-communicable diseases. ${ }^{96}$

Unlike acute treatment, there are few immediate and measureable results of prevention. ${ }^{76}$ However, focusing on particular events at a given point in time instead of framing a problem in terms of a pattern of behaviour over time is to fail to understand the nature of the continuum from normality to pathology in chronic disease. ${ }^{97}$

\section{Insufficient clinical training}

The disease-based model of healthcare has significantly influenced medical school curricula, and since the beginning of the 20th century, the primary goal for medical schools was to become more scientific and effective in the education of physicians. ${ }^{98}$ Since then, the structure of medical education has not varied significantly, and the importance of scientific knowledge and understanding of biomedical concepts is still acknowledged as a central pillar of the practice of medicine. ${ }^{99}$ Today's medical schools are seen as 'academic health science centres', complex institutions dedicated primarily and almost 
exclusively to biomedical research and managed care, to the growing detriment of undergraduate medical education. ${ }^{100}$ The pressure to obtain research grants, advance academic careers and bring in patient revenue leaves faculty with little choice but to work intently within their specialty silo. ${ }^{99} 101102$ One need look no further than the American Board of Medical Specialties, which lists 24 specialties and 121 subspecialties; integrating the information from these fields into a disease prevention curriculum would be overwhelming.

Education on preventive medicine is widely considered inadequate, and there is little experience offered in health promotion interviewing or prescribing physical activity. ${ }^{103} 104$ Students acquire sparse knowledge about prevention and team- and population-delivered care, and they see this field as unappealing as a career choice. ${ }^{105-108}$ The importance of including the subject of preventive medicine in medical degree programmes has been internationally recognised and has led to a number of initiatives to improve students' confidence, knowledge base and skills in incorporating prevention into routine healthcare. ${ }^{109-112}$ Even though many medical schools indicate their desire to improve teaching of primary and secondary prevention, sport and exercise medicine itself is not even part of the standard curriculum, ${ }^{113}$ nor does the specialty or subspecialty exist in all countries. More medical students believe lifestyle changes are important when they begin medical school than when they finish, ${ }^{114}$ showing the negative impact the current curricula have on the motivation of future healthcare providers regarding lifestyle behaviour. ${ }^{114-116}$

\section{Lack of a distribution channel for preventive healthcare services}

Physicians struggle to meet the need for preventive services in healthcare, and this is most obvious for primary prevention. It is not that physicians are unable to do this work. There is evidence that physical activity increases after physician counselling. ${ }^{117} 118$ But the day-to-day work of diagnosing and treating disease and all of the activities that flow from that focus comprise most physicians' workdays. Physicians are not trained in prevention, and there is little support for physician-directed preventive activities; there is no acknowledged prevention model to provide structure to the relationships between physicians and other healthcare professionals.

As a result, physician advice might be associated with shortterm increases in physical activity, but there is insufficient evidence of sustained changes. ${ }^{119-121}$ In the USA, $62 \%$ of the population consult physicians less than four times per year, including $15 \%$ with no visits at all. ${ }^{122}$ But the time needed to meet preventive, chronic and acute care requirements significantly exceeds the time physicians have available for patient care. ${ }^{123}$ The average of $2 \mathrm{~min}^{124}$ of health education per visit cannot have a population-wide impact on physical activity. Further barriers to physical activity counselling include insufficient knowledge and skills. ${ }^{119} 121125$ Lifestyle interventions are often related to physicians' own lifestyle habits, which may be no better than the general population. ${ }^{126} 127$ Our disease-based medical system cannot expect physicians to be the only care coordinators for every stage of chronic disease including its prevention.

\section{The complexity of behavioural change}

It is well established that approximately half of all causes of morbidity and mortality in the USA are linked to behavioural and social factors. Changing health behaviours is difficult. ${ }^{125}{ }^{128-131}$ Humans were designed for movement, ${ }^{132}$ but physical activity has been factored out of our daily routines. ${ }^{39}$ Maintaining and improving health competes against multiple, sometimes conflicting, objectives and consequently may not be seen as an essential goal. Although two thirds of the population desire more emphasis on chronic disease prevention, more than half the population fails to meet physical activity guidelines and one third engage in no regular leisure-time physical activity. ${ }^{4142}$ Generally speaking, people prefer an immediate benefit to a delayed one, even if the latter is larger. Similarly, they discount the longer-term negative consequences of an act that procures immediate gratification. ${ }^{133-135}$ Only the immediate and unpleasant consequences of a disease constitute ample motivation to adhere to therapeutic advice. ${ }^{83}$

\section{THE ROLE OF SPORT AND EXERCISE MEDICINE IN PREVENTING AND TREATING CHRONIC DISEASE}

There is an immediate need for clinical sport and exercise medicine to expand involvement and extend its expertise to chronic disease prevention and treatment.

Sport and exercise medicine has four decades of experience in exercise medicine, rehabilitation and human performance. Much effort has been dedicated to the care of athletes and those with musculoskeletal conditions. Recently, awareness of the need for implementation/dissemination research focused on public health and health promotion is increasing. ${ }^{136}$ In fact, the knowledge, skills and innovative leadership are transferable from the performance-oriented population to the prevention of chronic disease and maintenance of good health. Sport and exercise medicine emphasises functional capacity over disease diagnosis. In sport and exercise medicine, more important questions have been: 'When can I return to sport?' and 'How can I get active, fit and better more quickly?' These are questions about function. These questions require going beyond diagnosis and focus on functional capacity assessment to understand how the diagnosis impacts the patient's physical and daily activity. Many innovations in sport and exercise medicine have resulted from attempts to answer these questions.

Sport and exercise medicine's culture is multidisciplinary, integrated and holistic and ideally suited to take action in the areas of preventive and rehabilitative medicine using a multidisciplinary, holistic approach. For four decades, sport and exercise medicine clinicians have been required to treat the 'whole patient', which requires collaboration not only with medical specialties and other professions such as athletic training, physical therapy, nutrition and sport science, but also with coaches, administrators, sport agents, the media and legal groups.

Sport and exercise medicine has the advantage of being closely associated with organised sports that have great influence within many segments of society. Leveraging this influence is a unique strength that clinical sport and exercise medicine brings to the table of chronic disease prevention and management. As an example, FIFA established F-MARC (FIFA Medical Assessment and Research Centre) in 1994 to promote football as a health-enhancing activity. F-MARC's innovative initiative 'Football for Health' - '11 for Health' lies in its ability to align soccer's popularity with curricular changes that promote health in public schools within its 208 member nations, many of them developing countries. ${ }^{137}$ The successful nationwide implementation of 11 for Health in Mauritius in all schools is an excellent example of sport 'giving back' to medicine. ${ }^{138} 139$ Exercise 
is Medicine, organised through the American College of Sports Medicine, is an excellent example of a multifaceted programme of prevention targeting multiple points of entry from education to advocacy. ${ }^{140}$ In addition, the Swedish textbook providing exercise prescription for various chronic diseases has recently been translated into English. ${ }^{141} 142$

Finally, sport and exercise medicine is already leading the way. One need look no further than the recent trend to change the titles of longstanding 'sports medicine' to 'sport and exercise medicine' (American College of Sports Medicine and its Exercise is Medicine programme or the British, Canadian, Australian and German sports medicine societies recently adding the term 'exercise' or 'prevention' to their society names).

\section{THE SOLUTION IS TO BUILD A PATIENT-CENTRIC HEALTHCARE MODEL}

A fundamental tension exists between the values accorded primacy at the interface between prevention and diseasebased healthcare (figure 1). This explains a major part of the reason for the difficulties in advancing a health-based model to prevent and treat chronic disease. Failure to recognise this reality will keep us on a path that has not led to the healthcare transformation necessary for the prevention and management of chronic disease. We suggest that the prevention and management of chronic disease needs a new clinical home, one that understands and respects the need for acute, episodic care but, at the same time, advances the time-honored principles of prevention. This can begin in a small way, using the expertise and experience of sport and exercise physicians worldwide. Capacity can be built over time as successful ideas, developed and tested for proof of concept in smaller settings, are transferred to larger populations.

There are two main components to a new model of healthcare. One is technology and innovation and the other is the creation of a new profession.

\section{Modern health information technology, innovation, patient empowerment and user-centric care}

Disease-based healthcare encourages patient dependency on the medical system. To make the shift towards user-centric healthcare, we must empower patients to take responsibility for their own health. Some of this is accomplished by close supervision and personal instruction, with healthcare professionals applying communication skills such as motivational interviewing. ${ }^{143}$ However, the key will be to adopt modern technology to make health information instantly available, understandable and personally relevant. Tailored counselling that incorporates shared decision making, supportive materials and follow-up helps in changing behaviour. ${ }^{121} 144145$

Behavioural control and self-efficacy are effective comprehensive interventions alongside increasing self-regulatory skills. ${ }^{62}$ There is growing evidence that self-monitoring and behavioural change programmes using computer-tailored interfaces can be more effective in changing lifestyle risk factors than traditional approaches. ${ }^{146-149}$ Monitoring compliance and adherence is key to effecting behavioural change. People tend to overestimate time and intensity of their own physical activity. For example, $40 \%$ of adults claim to engage in physical activity sufficient to improve health but less than $4 \%$ actually do. ${ }^{150}$ But they behave differently when provided with detailed information of their behaviour using self-monitoring tools such as tracking devices. ${ }^{151}$ In the next 10 years, innovative medical technology will reduce the complexity of the collective influences of genetic vulnerability, epigenetic changes (such as environmental factors and biomolecular data combined with clinical findings) and render the outputs useful for rule-based care. ${ }^{152}$ High-performance computation will elucidate the complexity of a number of disease pathways, changing today's reactive position of treating disease to a proactive position of predicting disease risk and seeking to prevent or substantially slow the onset of severe disease. ${ }^{153} 154$ Personal, digital data is generating new possibilities for health management in terms of targeting interventions ${ }^{155}$ and has the potential to transform the face of health service delivery around the globe. ${ }^{156} 157$

The International Telecommunication Union estimates that by the end of $2010,77 \%$ of the world's population had a mobile phone and over $85 \%$ were covered by a mobile phone network. ${ }^{158}$ As the digital society is expected to grow more than 40 times in global volume in the next 10 years, tectonic shifts in health information economy must be expected, making possible abundant yet focused information for the patient and care giver. 159160 Once widely implemented, this environment will provide the foundation for digital applications and tools that enable interaction and collaboration in a way that users (patients) become participants (empowered co-creators not end users) strengthened through the network (a collective resource). ${ }^{143}$ Personal data will be the new 'oil', a valuable resource of the 21st century and a main driver in the conversion of an event-based health system in which the patient is a passive participant to a health-based approach in which the patient is more actively involved.

\section{A new profession must be created}

There is currently no profession that dedicates the majority of its efforts to the prevention and management of chronic lifestyle-related disease. This is an amazing oversight. Several professions already possess key components of the knowledge, skills and attitudes required, and some are actively applying their expertise to the prevention of chronic disease. These professions include athletic training/therapy, physical therapy, nursing, strength and conditioning, fitness instruction, exercise physiology and kinesiology. The larger medical profession needs to recognise and support these efforts and provide cohesion and structure for the work. This includes holding professional meetings that support growth in this area. As time passes, it is likely that a unified curriculum will be developed for this new profession that includes behavioural modification, innovative use of technology, population-based outcome assessment, exercise training and monitoring, rehabilitation, nutrition, illness and injury assessment and programme development. Although this is a natural progression within the field of prevention, creating a curriculum and structured profession is not required immediately and should not be yet another obstacle to forward movement. Many of the above-mentioned professions are already capable of meeting the challenge and would benefit from an umbrella organisation and a supportive educational and professional structure.

We can draw from the expertise of these professions to create a consensus curriculum, training programme and certification examination that would be attractive to students from these and other professions. This curriculum would include population epidemiology, chronic disease, rehabilitation, prevention, assessment skills, prescription, monitoring and testing of exercise prescriptions, nutrition, behavioural 


\section{In the short-term, fundamental differences between reductionism and holism are an impediment to solving the problem of chronic disease - this reality requires the \\ development of a new profession}

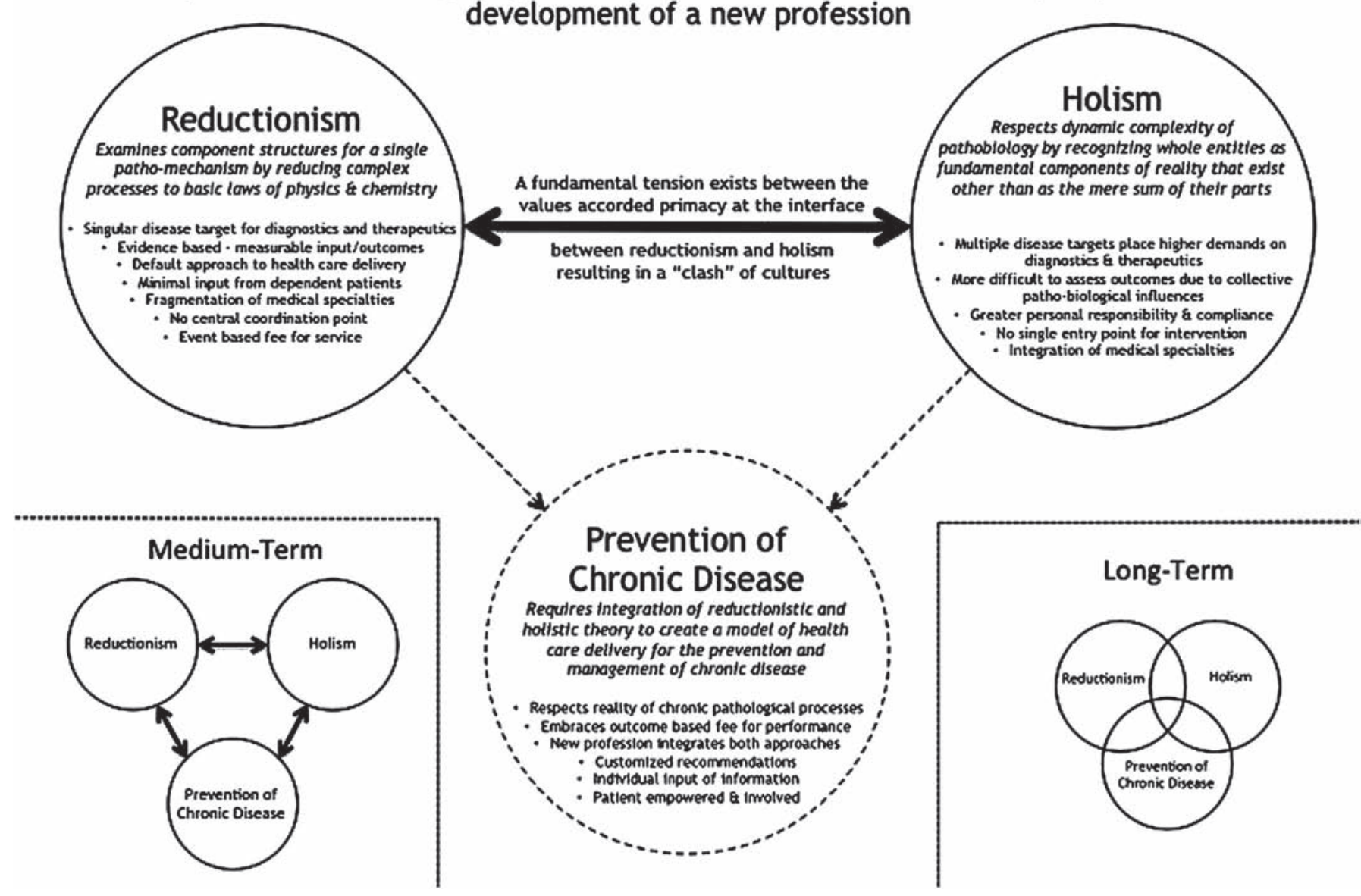

Figure 1 Reductionist theory states that complex data or phenomena can be explained by reduction to more simply understood, fundamental parts. Holistic theory believes that all the properties of a system cannot be determined or explained by its component parts. In effect, holism states that reality is interacting wholes that are more than the mere sum of their parts. Reductionism and holism are both part of our reality. Reductionism is most closely associated with medical science, whereas holism has been de-emphasised in part because its connotation includes metaphysics, complementary medicine and naturopathy. Reductionism has become the default strategy not only for medical science but also for medical care. The shortcomings of reductionism are apparent in the prevention and treatment of chronic diseases requiring a multidisciplinary, integrated approach. The fundamental tenets of holism and reductionism are so different that prevention has no fertile middle ground within which to develop. It is, in essence, an orphan. Sport and Exercise Medicine should adopt chronic disease prevention and management so that a new clinical home can be established to champion its cause. Healthcare providers in this new space would combine their training and education within disease-based, reductionist approaches for the treatment of acute disease episodes but would draw from the principles of populationbased prevention to create new clinical delivery programmes within a new profession. In this diagram, the dotted lines indicate the emergence of a new clinical discipline that acts as both a home and a champion for the prevention and treatment of chronic disease. The short-term goal is to establish this clinical circle of endeavour with links to reductionism and holism. Medium-term goals (bottom left) would be to develop solid lines of collaboration, drawing from the two fields and measuring outcome progress from the new model of preventive healthcare delivery. Long-term goals (bottom right) would be for the fields of reductionism and holism to learn enough from each other that the three circles overlap substantially. It is important to recognise this approach will take time. For now, for this new field of endeavour to come into existence, it needs to be its own entity and revolve around its own centre - the prevention and treatment of chronic disease.

modification and stress management. A new profession would emphasise self-care combined with repeated patientcentred counselling that respects patient autonomy, incorporates patient preferences and motivations and uses processes of change more likely to be successful with shared decision making. ${ }^{161} 162$ These new professionals would be trained to deal with acute exercise-related complications and work in a team setting with sport and exercise medicine physicians, especially for patients at higher risk.

This new profession would also present a substantial cost savings, providing hands-on, day-to-day instruction, education and follow-up on comprehensive lifestyle intervention in both group and individual settings. It would interface with the existing healthcare system through the sport and exercise medicine or trained primary care physician providing oversight, medical direction and supervision. Patientcentred model is based on (1) initial screening for risk factors of chronic disease or presence of existing chronic disease; (2) risk stratification of patients; and (3) implementation of a broad patient-centred lifestyle intervention programme that is medically supervised (patients at high risk) or medically directed (intermediate risk). A programme such as this has been successfully implemented in South Africa for a number of chronic diseases. ${ }^{163}$ 


\section{A VISION: SPORT AND EXERCISE MEDICINE IN PREVENTION AND PUBLIC HEALTH}

As the burden of chronic disease steadily increases, prevention must become our preferred approach over event-based treatment. Understanding interactions between individual health-related behaviours and the range of determinants that contribute to shape such behaviours is a fundamental step in the design of effective comprehensive interventions.

Our collective effort on physical activity for the prevention of chronic disease has been relatively ineffective. Physicians need to be incentivised to spend more time with patients related to prevention, and patients need to be incentivised to seek out this form of evaluation. And, to move forward, we must be willing to embrace new ideas.

The seedbeds of transformation are already being sewn by two simultaneous trends: lack of sustainability and new innovations. These trends are catalytic; new technologies empower patients, and economic pressures help speed adoption, break down resistance and realign incentives around changing business models that leverage these new technologies.

We are on the cusp of the third major square-wave adjustment to healthcare delivery: preventing and treating chronic disease. The first two major advances, widespread adoption of hygiene and effective curative medicines, devices and surgeries, have delivered substantial improvements in quality and length of human life. We now embark on an era where the major transformation will come from changed behaviours, not only in patients but also in the workplace, healthcare professionals, payers and medical schools will need to revisit and realign their practices to improve healthcare. Sport and exercise medicine should play a leading role in this transformation.

\section{Call to action}

The sport and exercise medicine physician community should immediately begin taking an active role in leading the transformation required in healthcare delivery to meet the needs of prevention and treatment of chronic disease through comprehensive lifestyle intervention. This requires not only collaboration and coordination but also leadership and oversight.

Clinical sport and exercise medicine has demonstrated its ability to innovate and lead. Immense potential for disease prevention lies within clinical sport and exercise medicine beginning with the transfer of its vast knowledge and skills to the general populace to effect prevention of chronic disease. We need to combine forces with multiple stakeholders, including other academic disciplines (eg, human behaviour, public health, epidemiology and healthcare delivery research), governmental bodies (eg, education ministries, transport, environmental design and city planning), technology industries (eg, social media companies), healthcare funders and international sports federations.

\footnotetext{
Aligning our professional societies around a prevention agenda Sport and exercise medicine societies consist of talented, creative, highly capable physicians who, if they collectively engage the problem, could rapidly advance the field of prevention. The leadership of these organisations should meet to establish a shared agenda for adopting the prevention and treatment of chronic disease within sport and exercise medicine. Suggestions for this agenda are provided below. The formation of coordinated working groups to tackle the unsolved questions and problems regarding the implementation of prevention would produce a fertile global collaboration.
}

These working groups, in effect 'thought leaders', would represent a commitment of purpose and identity within sport and exercise medicine associations and send the important message of solidarity through a global alliance related to this difficult problem.

\section{Coordinate proof of concept efforts}

Key questions are how a change towards prevention is going to be paid for and what is the description of an actual preventive programme. The first step in answering these questions is to identify successful examples of disease prevention programmes and study them in detail for the elements that are generalisable. This would lead to the development of much needed prevention business plans and curricular prototypes for professional training programmes. Once accomplished, this information could become part of a consolidated advocacy programme.

\section{Support the creation of a new type of healthcare professional}

The gap that exists between physician services and fitness training with respect to prevention is large and is best met through the consolidation of expertise within a new profession. This new profession would provide a coordinated entry point, focused in purpose and outcomes oriented. There are many young people highly interested in this field who would eagerly embrace prevention as a career if a training/certification programme were available. Whether this is based on an existing profession remains to be determined.

\section{Develop a curriculum in collaboration with other disciplines}

It is essential to develop a curriculum that defines the scope and depth of the knowledge, skills and attitude required for working in the area of chronic disease prevention and treatment. This curriculum need not be detailed in the beginning and could be based on existing curricula. Refinement can lead to the foundation of a new profession and assist in meeting the needs of regulatory and licensing bodies. The collaboration of leaders from sport and exercise medicine societies worldwide with professional associations and academic institutions graduating students in applied physiology and movement sciences will move the curriculum forward quickly.

\section{Organise international meetings}

Sport and exercise medicine societies could commit time in their annual scientific conferences to presentations and discussion on exercise medicine-related research. This would contribute to the rapid advancement of knowledge related to the implementation of preventive approaches to healthcare and would send a strong message to the society memberships regarding the importance of physical activity. We should follow the lead taken by the American College of Sports Medicine, which, in 2010, established an annual meeting (World Congress for Exercise is Medicine) held at the same time as its annual conference. Similarly, the Swedish Association of Sports and Exercise Medicine mandates that national Sports Medicine meetings should include symposia on physical activity prescription. ${ }^{141}$ Another example is the joint meeting between Arthritis UK and the British Association of Sport and Exercise Medicine held last November in London.

A biennial or triennial multidisciplinary global conference would cast a wide net for scientists, clinicians, educators and advocates with the support necessary to make progress. It would be important for this type of meeting to contain forum-like components that use approaches such as the National Institutes of Health consensus to focus on solutions 
from essential areas of technology, social media, behaviour, research, education, advocacy, economics, legislation and healthcare.

\section{Leverage the influence of sports federations for prevention}

Sport and Exercise Medicine has given a great deal to sport over the past 3-4 decades. It is time that sport reciprocates to the extent possible, and there is no better way than through advancing a global health agenda related to the prevention and management of chronic disease. A good example comes from FIFA F-MARC, which invites, every 3 years, physicians from their 208 national member associations to a Congress to discuss injury prevention and the impact of regular physical activity on the prevention of chronic disease, shifting the focus from medicine for football to football for health. These initiatives present an opportunity for affiliation with highlevel sport organisations that carry global influence.

\section{Collaborate with technology and develop partnerships}

Technology and social media collaborations are independent issues requiring focus. The goal is to connect the knowledge pool regarding comprehensive lifestyle interventions with the patient. Personal electronic health records will provide the connection that draws together the individual elements of healthcare and makes the abundance of information understandable for the patient and care giver. Personal electronic devices will also enable the important shift from patient dependency to personal responsibility.

\section{Centralise the publication of articles in academic journals}

The publication of useful, practical information regarding physical activity, exercise and disease prevention could be increased within the academic sports medicine journals that already exist. ${ }^{163}$ A piggyback approach could focus thought and research on the role for sport and exercise medicine practitioners with special sections or even issues of journals dedicated to the topic.

\section{CONCLUSION}

Forty years ago, sports medicine was a dream for some physicians and, at best, part-time work for others. It is now a flourishing medical discipline. Similarly, the prevention and treatment of chronic lifestyle-related disease is currently a dream for some and, at best, part-time work for others. It should be full-time work for many of us. The global epidemic of chronic disease and its treatment through comprehensive lifestyle intervention requires a new approach to healthcare delivery; a health-based model. The international sport and exercise medicine community can provide leadership, expertise and labourers for change. This requires a coordinated strategy to harness the wealth of creativity and innovation that has been so successful in building clinical sports medicine over the past four decades. The substantial burden of chronic disease coupled with existing medical delivery systems are crippling attempts to innovate preventive approaches and are the exact call to action that clinical sports medicine responded to 40 years ago.

Contributors Each of the authors on this article contributed ideas and specific text to the article in a substantial way.

Acknowledgements The authors gratefully acknowledge the valuable assistance of Dr Katharnina Grimm, Dr Don McKenzie, Dr Evert Verhagen and Dr Mark Batt in reviewing this manuscript.

Competing interests None.
Provenance and peer review Not commissioned; externally peer reviewed.

\section{REFERENCES}

1. Faculty of Sport and Exercise Medicine. FSEM Professional Code. 2010. http:// www.fsem.co.uk/DesktopModules/Documents/DocumentsView.aspx?tabID=0 \&ltemID=115172\&MId=5261\&wversion=Staging (accessed 17 June 2011).

2. Klügl M, Shrier I, McBain K, et al. The prevention of sport injury: an analysis of 12,000 published manuscripts. Clin J Sport Med 2010;20:407-12.

3. Haskell WL, Lee IM, Pate RR, et al. Physical activity and public health: updated recommendation for adults from the American College of Sports Medicine and the American Heart Association. Med Sci Sports Exerc 2007;39:1423-34.

4. Pate RR, Pratt M, Blair SN, et al. Physical activity and public health. A recommendation from the Centers for Disease Control and Prevention and the American College of Sports Medicine. JAMA 1995;273:402-7.

5. Bouchard C, Shephard RJ, Stepens T, et al. Physical Activity, Fitness, and Health: International Proceedings and Consensus Statement. Champaign, IL: Human Kinetics Publishers 1994.

6. Finch CF, Donaldson A. A sports setting matrix for understanding the implementation context for community sport. Br J Sports Med 2010;44:973-8.

7. Kumanyika SK, Obarzanek E, Stettler N, et al. Population-based prevention of obesity: the need for comprehensive promotion of healthful eating, physical activity, and energy balance: a scientific statement from American Heart Association Council on Epidemiology and Prevention, Interdisciplinary Committee for Prevention (formerly the expert panel on population and prevention science). Circulation 2008;118:428-64.

8. Lin JS, O'Connor E, Whitlock EP, et al. Behavioral counseling to promote physical activity and a healthful diet to prevent cardiovascular disease in adults: a systematic review for the U.S. Preventive Services Task Force. Ann Intern Med 2010;153:736-50.

9. Ross R, Blair SN, Godwin M, et al. Prevention and Reduction of Obesity through Active Living (PROACTIVE): rationale, design and methods. Br J Sports Med 2009;43:57-63.

10. Warburton DE, Katzmarzyk PT, Rhodes RE, et al. [Evidence-based guidelines for physical activity of adult Canadians]. Appl Physiol Nutr Metab 2007;32(Suppl 2F):S17-74.

11. Kannel WB, Sorlie P. Some health benefits of physical activity. The Framingham Study. Arch Intern Med 1979;139:857-61.

12. Paffenbarger RS Jr, Hyde RT, Wing AL, et al. The association of changes in physical-activity level and other lifestyle characteristics with mortality among men. N Engl J Med 1993;328:538-45.

13. Helmrich SP, Ragland DR, Leung RW, et al. Physical activity and reduced occurrence of non-insulin-dependent diabetes mellitus. N Engl J Med 1991;325:147-52.

14. Hooi JD, Kester AD, Stoffers HE, et al. Incidence of and risk factors for asymptomatic peripheral arterial occlusive disease: a longitudinal study. Am J Epidemiol 2001;153:666-72.

15. Morris JN, Clayton DG, Everitt MG, et al. Exercise in leisure time: coronary attack and death rates. Br Heart J 1990;63:325-34.

16. Morris JN, Everitt MG, Pollard R, et al. Vigorous exercise in leisure-time: protection against coronary heart disease. Lancet 1980;2:1207-10.

17. Lee CD, Folsom AR, Blair SN. Physical activity and stroke risk: a meta-analysis Stroke 2003;34:2475-81.

18. Rasmussen $\mathbf{F}$, Lambrechtsen J, Siersted HC, et al. Low physical fitness in childhood is associated with the development of asthma in young adulthood: the Odense schoolchild study. Eur Respir J 2000;16:866-70.

19. Wannamethee SG, Shaper AG, Walker M. Changes in physical activity, mortality, and incidence of coronary heart disease in older men. Lancet 1998;351:1603-8.

20. Church TS, Kampert JB, Gibbons LW, et al. Usefulness of cardiorespiratory fitness as a predictor of all-cause and cardiovascular disease mortality in men with systemic hypertension. Am J Cardiol 2001;88:651-6.

21. Kallings LV, Sierra Johnson J, Fisher RM, et al. Beneficial effects of individualized physical activity on prescription on body composition and cardiometabolic risk factors: results from a randomized controlled trial. Eur J Cardiovasc Prev Rehabil 2009;16:80-4.

22. Knowler WC, Barrett-Connor E, Fowler SE, et al. Reduction in the incidence of type 2 diabetes with lifestyle intervention or metformin. N Engl J Med 2002;346:393-403.

23. Schmitz KH, Ahmed RL, Troxel AB, et al. Weight lifting for women at risk for breast cancer-related lymphedema: a randomized trial. JAMA 2010;304:2699-705.

24. Calle EE, Rodriguez C, Walker-Thurmond K, et al. Overweight, obesity, and mortality from cancer in a prospectively studied cohort of U.S. adults. N Engl J Med 2003;348:1625-38.

25. Rastogi T, Vaz M, Spiegelman D, et al. Physical activity and risk of coronary heart disease in India. Int J Epidemiol 2004;33:759-67. 
26. Leeder S, Raymond S, Greenberg H, et al. A Race Against Time: The Challenge of Cardiovascular Disease in Developing Countries. New York, NY: Trustees of Columbia University 2004.

27. Matthews CE, Jurj AL, Shu XO, et al. Influence of exercise, walking, cycling, and overall nonexercise physical activity on mortality in Chinese women. Am J Epidemiol 2007;165:1343-50.

28. Proper KI, Singh AS, van Mechelen W, et al. Sedentary behaviors and health outcomes among adults: a systematic review of prospective studies. Am J Prev Med 2011;40:174-82

29. Hickman IJ, Jonsson JR, Prins JB, et al. Modest weight loss and physical activity in overweight patients with chronic liver disease results in sustained improvements in alanine aminotransferase, fasting insulin, and quality of life. Gut 2004:53:413-19.

30. Courneya KS, Friedenreich CM. Physical exercise and quality of life following cancer diagnosis: a literature review. Ann Behav Med 1999;21:171-9.

31. Cassilhas RC, Viana VA, Grassmann V, et al. The impact of resistance exercise on the cognitive function of the elderly. Med Sci Sports Exerc 2007;39:1401-7.

32. Lee CD, Blair SN, Jackson AS. Cardiorespiratory fitness, body composition, and allcause and cardiovascular disease mortality in men. Am J Clin Nutr 1999;69:373-80.

33. Marcus BH, Albrecht AE, King TK, et al. The efficacy of exercise as an aid for smoking cessation in women: a randomized controlled trial. Arch Intern Med 1999;159:1229-34.

34. Wadden TA, Butryn ML, Byrne KJ. Efficacy of lifestyle modification for long-term weight control. Obes Res 2004;12(Suppl):151S-62S

35. Gates DM, Succop P, Brehm BJ, et al. Obesity and presenteeism: the impact of body mass index on workplace productivity. J Occup Environ Med 2008;50:39-45.

36. Brunello G, Michaud PC, Sanz-de-Galdeano A. The rise of obesity in Europe: an economic perspective. Econ Pol 2009;24: 551-96.

37. Popkin BM, Kim S, Rusev ER, et al. Measuring the full economic costs of diet, physical activity and obesity-related chronic diseases. Obes Rev 2006; 7:271-93

38. Weiler R, Feldschreiber P, Stamatakis E. Medicolegal neglect? The case for physical activity promotion and Exercise Medicine. Br J Sports Med 2011; (In Press).

39. Sassi F. Obesity and the Economics of Prevention - Fit Not Fat. OECD, 2010. http://www.oecd.org/health/fitnotfat (accessed 17 June 2011)

40. Björck L, Rosengren A, Bennett K, et al. Modelling the decreasing coronary heart disease mortality in Sweden between 1986 and 2002. Eur Heart J 2009:30:1046-56.

41. Pleis JR, Lucas JW, Ward BW. Summary health statistics for U.S. adults: National Health Interview Survey, 2008. Vital Health Stat 10 2009:242:1-157.

42. Canadian Fitness and Lifestyle Research Institute. 2002 Physical Activity Monitor. http://www.cflri.ca/eng/statistics/surveys/pam2002.php laccessed 17 June 2011)

43. Daar AS, Singer PA, Persad DL, et al. Grand challenges in chronic noncommunicable diseases. Nature 2007:450:494-6.

44. Kung HC, Hoyert DL, Xu J, et al. Deaths: final data for 2005. Natl Vital Stat Rep 2008:56:1-120

45. Wu SY, Green A. Projection of Chronic Illness Prevalence and Cost Inflation. Santa Monica, CA: RAND, 2000

46. Anderson G, Horvath J, Knickman JR, et al. Chronic Conditions: Making the Case for Ongoing Care: September 2004 Update. Partnership for Solutions: John Hopkins University, 2004

47. World Health Organization. Preventing Chronic Diseases: A Vital Investment WHO Global Report. 2005. http://www.who.int/chp/chronic_disease_report/ contents/en/index.html (accessed 17 June 2011)

48. Dans A, Ng N, Varghese C, et al. The rise of chronic non-communicable diseases in southeast Asia: time for action. Lancet 2011;377:680-9.

49. United Nations. The Millenium Development Goals Report 2009. 2009. http:// www.un.org/millenniumgoals/pdf/MDG_Report_2009_ENG.pdf laccessed 17 June 2011).

50. Mathers CD, Loncar D. Projections of global mortality and burden of disease from 2002 to 2030. PLoS Med 2006; 3:e442.

51. Sassi F, Devaux M, Cecchini M, et al. The Obesity Epidemic: Analysis of Past and Projected Future Trends in Selected OECD Countries. OECD Health Working Paper No 45. Paris: OECD Publishing, 2009.

52. Prentice AM, Jebb SA. Obesity in Britain: gluttony or sloth? BMJ 1995; 311:437-9

53. Bassett DR, Schneider PL, Huntington GE. Physical activity in an Old Order Amish community. Med Sci Sports Exerc 2004;36:79-85.

54. Church TS, Thomas DM, Tudor-Locke C, et al. Trends over 5 decades in U.S. occupation-related physical activity and their associations with obesity. PLOS ONE 2011;6:e19657

55. Abegunde DO, Mathers CD, Adam T, et al. The burden and costs of chronic diseases in low-income and middle-income countries. Lancet 2007; 370:1929-38.
56. Cawley J, Rizzo JA, Haas K. Occupation-specific absenteeism costs associated with obesity and morbid obesity. J Occup Environ Med 2007:49:1317-24.

57. Finkelstein E, Fiebelkorn C, Wang G. The costs of obesity among full-time employees. Am J Health Promot 2005;20:45-51.

58. World Health Organization. The Global Burden of Disease: 2004 Update. 2008. http://www.who.int/healthinfo/global_burden_disease/GBD_report_2004update_ full.pdf (accessed 17 June 2011).

59. Wang Y, Beydoun MA, Liang L, et al. Will all Americans become overweight or obese? estimating the progression and cost of the US obesity epidemic. Obesity (Silver Spring) 2008;16:2323-30.

60. United Nations General Assembly. Scope, Modalities, Format and Organization of the High-Level Meeting of the General Assembly on the Prevention and Control of Non-Communicable Diseases. 2010. http://www.who.int/nmh/publications/ un65 238 en.pdf (accessed 17 June 2011).

61. Baranowski T, Anderson C, Carmack C. Mediating variable framework in physical activity interventions. How are we doing? How might we do better? Am J Prev Med 1998;15:266-97.

62. Rhodes RE, Pfaeffli LA. Mediators of physical activity behaviour change among adult non-clinical populations: a review update. Int J Behav Nutr Phys Act 2010;7:37.

63. Marcus BH, Owen N, Forsyth $\mathrm{LH}$, et al. Physical activity interventions using mass media, print media, and information technology. Am J Prev Med 1998;15:362-78

64. Cavill N, Bauman A. Changing the way people think about health-enhancing physical activity: do mass media campaigns have a role? J Sports Sci 2004:22:771-90.

65. Vandelanotte C, Spathonis KM, Eakin EG, et al. Website-delivered physical activity interventions a review of the literature. Am J Prev Med 2007;33:54-64.

66. Kliman AM, Rhodes R. Do government brochures affect physical activity cognition? A pilot study of Canada's physical activity guide to healthy active living Psychol Health Med 2008:13:415-22.

67. Marshall AL, Leslie ER, Bauman AE, et al. Print versus website physical activity programs: a randomized trial. Am J Prev Med 2003;25:88-94.

68. Harris KC, Kuramoto LK, Schulzer M, et al. Effect of school-based physical activity interventions on body mass index in children: a meta-analysis. CMAJ 2009;180:719-26.

69. Abraham C, Graham-Rowe E. Are worksite interventions effective in increasing physical activity? A systematic review and meta-analysis. Health Psychol Rev 2009; 3:108-44.

70. Goetzel RZ, Ozminkowski RJ, Bruno JA, et al. The long-term impact of Johnson $\&$ Johnson's Health \& Wellness Program on employee health risks. J Occup Environ Med 2002:44:417-24.

71. World Economic Forum. The New Discipline of Workforce Wellness Enhancing Corporate Performance by Tackling Chronic Disease. 2010. http://alliance.weforum.org/Downloads/Wellness\%20Tools/BCG-Report NewDisciplineWorkforceWellness.pdf (accessed 17 June 2011).

72. Pritchard DA, Hyndman J, Taba F. Nutritional counselling in general practice: a cost effective analysis. J Epidemiol Community Health 1999;53:311-16.

73. Proper K, van Mechelen W. Effectiveness and Economic Impact of Worksite Interventions to Promote Physical Activity and Healthy Diet. Geneva: World Health Organization, 2008. http://www.who.int/dietphysicalactivity/Proper_K.pdf laccessed 17 June 2011)

74. Ockene IS, Hebert JR, Ockene JK, et al. Effect of training and a structured office practice on physician-delivered nutrition counseling: the Worcester-Area Trial for Counseling in Hyperlipidemia (WATCH). Am J Prev Med 1996:12:252-8.

75. Allotey P, Reidpath DD, Yasin S, et al. Rethinking health-care systems: a focus on chronicity. Lancet 2011;377:450-1.

76. Ahn AC, Tewari M, Poon CS, et al. The clinical applications of a systems approach. PLoS Med 2006; 3:e209

77. Christensen CM, Bohmer R, Kenagy J. Will disruptive innovations cure health care? Harv Bus Rev 2000;78:102-12, 199

78. Ahn AC, Tewari M, Poon CS, et al. The limits of reductionism in medicine: could systems biology offer an alternative? PLoS Med 2006; 3:e208.

79. National Institute of Diabetes \& Digestive \& Kidney Diseases. Action for Health in Diabetes (Look AHEAD). 2009. https://www.lookaheadtrial.org (accessed 17 June 2011).

80. Tugwell P, de Savigny D, Hawker G, et al. Applying clinical epidemiological methods to health equity: the equity effectiveness loop. BMJ 2006;332:358-61.

81. Pham HH, Ginsburg PB. Unhealthy trends: the future of physician services. Health Aff (Millwood) 2007; 26:1586-98.

82. Berenson RA, Horvath J. Confronting the barriers to chronic care management in Medicare. Health Aff (Millwood) 2003;Suppl Web Exclusives:W3-37-53.

83. Christensen CM, Grossmann JH, Hwang J. The Innovator's Prescription: A Disruptive Solution for Health Care. Columbus, OH: McGraw-Hill 2008.

84. Porter ME. What is value in health care? N Engl J Med 2010;363:2477-81.

85. Laupacis A, Keown P, Pus N, et al. A study of the quality of life and cost-utility of renal transplantation. Kidney Int 1996;50:235-42. 
86. Ofri D. Quality measures and the individual physician. N Eng/ J Med 2010;363:606-7.

87. Martin RL. The Design of Business - Why Design Thinking is the Next Competitive Advantage. Boston, MA: Harvard Business School Press 2009

88. Office of Disease Prevention and Health Promotion. Healthy People 2020 Summary of Objectives. http://www.healthypeople.gov/2020/ topicsobjectives2020/pdfs/EducationalPrograms.pdf (accessed 17 June 2011).

89. Ginsburg PB, Grossman JM. When the price isn't right: how inadvertent payment incentives drive medical care. Health Aff 2005;5:376-84. http://content.healthaffairs. org/content/early/2005/08/09/hlthaff.w5.376.short (accessed 17 June 2011).

90. Dacey B. Coding: Preventive Services; ICD-10, New ABN Form. http://www. physicianspractice.com/coding/content/article/1462168/1751482 (accessed 17 June 2011).

91. Pham HH, Ginsburg PB, Lake TK, et al. Episode-based payments: charting a course for health care payment reform. Policy Analysis, National Institute For Health Care Reform 2010;1:1-16.

92. Pollak A. Doctors seek way to treat muscle loss. The New York Times, 30 August 2010

93. Walston J, Hadley EC, Ferrucci L, et al. Research agenda for frailty in older adults: toward a better understanding of physiology and etiology: summary from the American Geriatrics Society/National Institute on Aging Research Conference on Frailty in Older Adults. J Am Geriatr Soc 2006;54:991-1001.

94. Taaffe. Sarcopenia. Exercise as a treatment strategy. Aust Fam Physician 2006; 35:130-3.

95. Lins NE, Jones CM, Nilson JR. New frontiers for the sustainable prevention and control of non-communicable diseases (NCDs): a view from sub-Saharan Africa. Glob Health Promot 2010:17:27-30.

96. World Health Organization. Innovative Care for Chronic Conditions: Building Blocks for Action. 2002. http://www.who.int/diabetesactiononline/about/ icccglobalreport.pdf (accessed 17 June 2011)

97. Richmond B. The 'Thinking' in Systems Thinking: Seven Essential Skills (Toolbox Reprint Series). Waltham, MA: Pegasus Communications 2000.

98. Flexner A. Medical education in the United States and Canada. From the Carnegie Foundation for the Advancement of Teaching, Bulletin Number Four, 1910. Bull World Health Organ 2002;80:594-602.

99. Ludmerer KM. Learning to Heal: The Development of American Medical Education. New York, NY: Basic Books 1985.

100. Abrahamson $\mathbf{S}$. Time to return medical schools to their primary purpose: education. Acad Med 1996;11:343-7.

101. Abrahamson $\mathbf{S}$. The dominance of research in staffing of medical schools: time for a change? Lancet 1991; 337:1586-8

102. Cooke M, Irby DM, Sullivan W, et al. American medical education 100 years after the Flexner report. N Engl J Med 2006;355:1339-44.

103. Mohler MJ, D'Huyvetter K, Tomasa L, et al. Healthy aging rounds: using healthy-aging mentors to teach medical students about physical activity and social support assessment, interviewing, and prescription. J Am Geriatr Soc 2010;58:2407-11.

104. Gottlieb LK, Holman HR. What's preventing more prevention? Barriers to development at academic medical centers. J Gen Intern Med 1992;7:630-5.

105. Bohmer. Designing Care: Aligning the Nature and Management of Health Care. Boston, MA: Harvard Business Press 2009

106. Klement A, Bretschneider K, Lautenschlaeger C, et al. Prevention and health promotion in undergraduate medical education: preferences, attitudes and previous knowledge of medical students - a cross-sectional study GMS Z Med Ausbild 2011;28:1-15.

107. Chamberlain LJ, Wang NE, Ho ET, et al. Integrating collaborative population health projects into a medical student curriculum at Stanford. Acad Med 2008;83:338-44

108. Brun D, Hassid S, d'Ivernois JF. [How do physicians evaluate their medical schoo training. Retrospective survey of 4 groups of medical students 8-11 years after graduation]. Presse Med 1999;28:1121-7.

109. Liaison Committee on Medical Edutcation. Functions and Structure of a Medical School. 2003. http://www.lcme.org/functions2003march.pdf laccessed 17 June 2011)

110. Pomrehn PR, Davis MV, Chen DW, et al. Prevention for the 21st century: setting the context through undergraduate medical education. Acad Med 2000;75:S5-13.

111. Global Consensus for Social Accountability of Medical Schools. 2010. http:// healthsocialaccountability.sites.olt.ubc.ca/files/2011/06/11-06-07-GCSA-Englishpdf-style.pdf (accessed 17 June 2011).

112. Wylie A, Thompson S. Establishing health promotion in the modern medical curriculum: a case study. Med Teach 2007;29:766-71.

113. Garr DR, Lackland DT, Wilson DB. Prevention education and evaluation in U.S. medical schools: a status report. Acad Med 2000;75:S14-21.

114. Frank E, Tong E, Lobelo F, et al. Physical activity levels and counseling practices of U.S. medical students. Med Sci Sports Exerc 2008;40:413-21.

115. Lobelo F, Duperly J, Frank E. Physical activity habits of doctors and medical students influence their counselling practices. Br J Sports Med 2009;43:89-92.
116. Moynihan R. Doctors' education: the invisible influence of drug company sponsorship. BMJ 2008;336:416-17.

117. van Sluijs EM, van Poppel MN, Stalman WA, et al. Feasibility and acceptability of a physical activity promotion programme in general practice. Fam Pract 2004;21:429-36.

118. Kallings LV, Leijon M, Hellénius ML, et al. Physical activity on prescription in primary health care: a follow-up of physical activity level and quality of life. Scand J Med Sci Sports 2008;18:154-61.

119. Eakin EG, Smith B, Bauman A. Evaluating the populaion health impact of physical activity interventions in primary care - are we asking the right questions? $J$ Phys Act Health 2005;2:197-215.

120. Eden KB, Orleans CT, Mulrow CD, et al. Does counseling by clinicians improve physical activity? A summary of the evidence for the U.S. Preventive Services Task Force. Ann Intern Med 2002;137:208-15.

121. Merlwether RA, Wilcox S, Parra-Medina D. Physical activity interventions in clinical settings. Curr Cardiovasc Risk Rep 2007:1:237-46.

122. National Center for Health Statistics. Health, United States, 2010: With Special Feature on Death and Dying. 2011. http://www.cdc.gov/nchs/data/hus/hus10.pdf (accessed 17 June 2011).

123. Østbye T, Yarnall KS, Krause KM, et al. Is there time for management of patients with chronic diseases in primary care? Ann Fam Med 2005;3:209-14.

124. Stange KC, Woolf SH, Gjeltema K. One minute for prevention: the power of leveraging to fulfill the promise of health behavior counseling. Am J Prev Med 2002;22:320-3

125. Moser EM, Stagnaro-Green A. Teaching behavior change concepts and skills during the third-year medicine clerkship. Acad Med 2009;84:851-8.

126. Garry JP, Diamond JJ, Whitley TW. Physical activity curricula in medical schools. Acad Med 2002;77:818-20.

127. McKenna J, Naylor PJ, McDowell N. Barriers to physical activity promotion by general practitioners and practice nurses. Br J Sports Med 1998;32:242-7.

128. McGinnis JM, Foege WH. Actual causes of death in the United States. JAMA 1993;270:2207-12

129. Freid VM, Prager K, MacKay AP, et al. Chartbook on Trends in Health of Americans. Health, United States, 2003. National Center for Health Statistics. http://www.cdc.gov/nchs/data/hus/hus03.pdf (accessed 17 June 2011).

130. Song C, Ou Z, Blumm N, et al. Limits of predictability in human mobility. Science 2010;327:1018-21

131. Prochaska J0, Velicer WF, Rossi JS, et al. Stages of change and decisional balance for 12 problem behaviors. Health Psychol 1994;13:39-46.

132. Sparling PB, Owen N, Lambert EV, et al. Promoting physical activity: the new imperative for public health. Health Educ Res 2000;15:367-76.

133. O'Donoghue T, Rabin M. Doing it now or later. Am Eco Rev 1999:89:103-24.

134. Scharff R. Obesity and hyperbolic discounting: evidence and implications. $J$ Consum Pol 2009:32:3-21.

135. Stein RE, Bauman LJ, Ireys HT. Who enrolls in prevention trials? Discordance in perception of risk by professionals and participants. Am J Community Psychol 1991;19:603-17.

136. Finch CF. Implementation and dissemination research: the time has come! Br J Sports Med 2011:45:763-4

137. Blatter JS, Dvorak J. Football for health - prevention is better than cure Scand J Med Sci Sports 2010;20(Suppl 1):v.

138. Fuller CW, Junge A, DeCelles J, et al. 'Football for Health' - a football-based health-promotion programme for children in South Africa: a parallel cohort study. Br J Sports Med 2010;44:546-54.

139. Fuller CW, Junge A, Dorasami C, et al. ' 11 for Health', a football-based health education programme for children: a two-cohort study in Mauritius and Zimbabwe. Br J Sports Med 2011;45:612-18.

140. Jonas S. Phillips EM. ACSM's Exercise is Medicine - A Clinician's Guide to Exercise Prescription. Philadelphia, PA: Lippincott Williams \& Wilkins 2009.

141. Khan K. The girl with or without tattoos who lived happily ever after because of 'physical activity on prescription': the fourth in the Stieg Larsson Trilogy. Br J Sports Med 2011:45:157.

142. Hellénius ML, Sundberg CJ. Physical activity as medicine: time to translate evidence into clinical practice. Br J Sports Med 2011:45:158

143. Groeneveld IF, Proper KI, van der Beek AJ, et al. Sustained body weight reduction by an individual-based lifestyle intervention for workers in the construction industry at risk for cardiovascular disease: results of a randomized controlled trial. Prev Med 2010;51:240-6.

144. Jacobson DM, Strohecker L, Compton MT, et al. Physical activity counseling in the adult primary care setting: position statement of the American College of Preventive Medicine. Am J Prev Med 2005:29:158-62.

145. Whitlock EP, Orleans CT, Pender N, et al. Evaluating primary care behavioral counseling interventions: an evidence-based approach. Am J Prev Med 2002;22:267-84

146. Kroeze W, Werkman A, Brug J. A systematic review of randomized trials on the effectiveness of computer-tailored education on physical activity and dietary behaviors. Ann Behav Med 2006;31:205-23. 
147. Neville LM, O'Hara B, Milat AJ. Computer-tailored dietary behaviour change interventions: a systematic review. Health Educ Res 2009;24:699-720.

148. van den Berg MH, Schoones JW, Vliet Vlieland TP. Internet-based physical activity interventions: a systematic review of the literature. J Med Internet Res 2007; $9: \mathrm{e} 26$

149. Marcus BH, Nigg CR, Riebe D, et al. Interactive communication strategies: implications for population-based physical-activity promotion. Am J Prev Med 2000;19:121-6.

150. Troiano RP, Berrigan D, Dodd KW, et al. Physical activity in the United States measured by accelerometer. Med Sci Sports Exerc 2008;40:181-8.

151. Tudor-Locke CE, Myers AM, Bell RC, et al. Preliminary outcome evaluation of the First Step Program: a daily physical activity intervention for individuals with type 2 diabetes. Patient Educ Couns 2002;47:23-8.

152. Federoff HJ, Gostin LO. Evolving from reductionism to holism: is there a future for systems medicine? JAMA 2009;302:994-6.

153. Boguski MS, Arnaout R, Hill C. Customized care 2020: how medical sequencing and network biology will enable personalized medicine. F1000 Biol Rep 2009;1:73.

154. Emilsson V, Thorleifsson G, Zhang B, et al. Genetics of gene expression and its effect on disease. Nature 2008:452:423-8

155. World Economic Forum. Personal Data: The Emergence of a New Asset Class. 2011. http://www3.weforum.org/docs/WEF_ITTC_PersonalDataNewAsset Report_2011.pdf (accessed 17 June 2011).
156. World Health Organization. mHealth: New Horizons for Health through mobile Technologies: Second Global Survey on eHealth. WHO Library, 2011. http://www. who.int/goe/publications/goe_mhealth_web.pdf (accessed 17 June 2011).

157. Zurovac D, Sudoi RK, Akhwale WS, et al. The effect of mobile phone textmessage reminders on Kenyan health workers' adherence to malaria treatment guidelines: a cluster randomised trial. Lancet 2011;378:795-803.

158. Union IT. The World in 2010: ICT Facts and Figures. 2010. http://www.itu.int/ ITU-D/ict/material/FactsFigures2010.pdf (accessed 17 June 2011).

159. IDC. The Digital Universe Decade - Are You Ready? 2010. http://www.emc.com/ digital universe (accessed 17 June 2011).

160. MandI KD, Kohane IS. Tectonic shifts in the health information economy. N Engl J Med 2008;358:1732-7.

161. Bodenheimer T, Wagner EH, Grumbach K. Improving primary care for patients with chronic illness: the chronic care model, Part 2. JAMA 2002;288:1909-14.

162. Norris SL, Engelgau MM, Narayan KM. Effectiveness of self-management training in type 2 diabetes: a systematic review of randomized controlled trials. Diabetes Care 2001:24:561-87.

163. Derman EW, Patel DN, Nossel CJ, et al. Healthy lifestyle interventions in general practice - part 1: an introduction to lifestyle and diseases of lifestyle. SA Fam Pract 2008; 50:6-12. 